\title{
Pyridinolcarbamate in the Treatment of Ischemic Heart Diseases
}

\author{
A Double Blind Study
}

Santiago V. GuZman, M.D.*

\begin{abstract}
SUMmaRY
Thirty-four out-patients with electrocardiographic evidence of ischemic heart disease were divided into 2 groups, each group comprising of patients closely matched as to variables of sex, age, severity of symptoms and EGG findings. One group received pyridinolcarbamate, $1,500 \mathrm{mg}$. in 3 divided doses, while the other group received placebo. The response to the therapy in each group was evaluated on the basis of (a) physical work capacity (PWC) (b) nitroglycerine requirement and (c) electrocardiogram. The group that received pyridinolcarbamate showed a statistically significant $(\mathrm{p}<0.025)$ favorable response in the 3 parameters evaluated (PWC, nitroglycerine requirement and ECG) compared to the placebo group. The possible mechanism of action of the agent is discussed.
\end{abstract}

\section{Additional Indexing Words :}

Angina pectoris

Ischemic heart disease

Atherosclerosis

Pyridinolcarbamate

Treadmill exercise ECG test

$\mathrm{I}^{\mathrm{N}}$ $\mathrm{N}$ recent years, there has been considerable interest in the use of pyridinolcarbamate as an anti-atherosclerotic agent. ${ }^{1-3)}$ It has been shown to protect the arterial wall from cholesterol deposition and from the formation of atheroma in cholesterol fed rabbits with severe hypercholesteremia. ${ }^{4)}$ It has also been demonstrated that after a long term treatment with pyridinolcarbamate, absorption of the experimentally induced atheromatous mass occurred by replacement of the mass by regenerated smooth muscle fibers as well as collagenous and elastic fibers. ") While the current drug therapy for ischemic heart disease entails the use of vasoactive substances and beta-blockers, this compound is directed to the basic pathology of coronary artery disease. If atherogenesis in experimental animals apply to man, then the use of pyridinolcarbamate would be a great stride in the therapy of ischemic heart disease. It is the purpose of this study to evaluate the effects of this compound in patients with coronary heart disease.

From the Department of Physiology, College of Medicine, University of the Philippines.

* With the technical assistance of Mr. Victor Mendoza and Miss Iluminada Mamaat.

Received for publication September 3, 1971. 


\section{Materials AND Methods}

The subjects in the study consist of non-hospitalized patients with ischemic $\mathrm{ST}-\mathrm{T}$ depression of $1 \mathrm{~mm}$. or more in the resting or post-exercise electrocardiogram. There were 50 patients at the start of the study, 14 females and 36 males with ages varying from 41 to 68 years. They were divided into groups $\mathrm{A}$ and $\mathrm{B}$; each group comprising of subjects closely matched as to variables of sex, age, severity of symptoms and ECG findings.

Each patient was subjected to a treadmill exercise ECG test ${ }^{5)}$ up to a point of angina and/or ischemic ST changes before and at varying periods during the evaluation of the drug. Routine clinical tests were also performed in all cases before and after the termination of the study. These studies consist of routine urinalysis, blood sugar, cholesterol and uric acid and chest X-ray. Baseline observations were made of physical effort (distance covered in the treadmill walk) to elicit angina and nitroglycerine requirements per day or number of anginal attacks per week. The patients in each group were then given a standard medication of pentaerythrital tetranitrate (PETN), $10 \mathrm{mg}$. and t.i.d., and nitroglycerine as needed for chest pain. In one group pyridinolcarbamate $1,500 \mathrm{mg}$. in 3 divided doses was given, and placebo for the other group (the identity of the drug is not known to the investigator). Each patient was followed up at 4-6 weeks interval for a period of 2-6 months. During each visit, the clinical cause or internal history of the patient was noted and the resting or exercise ECG was done.

\section{RESULtS}

Of the 50 patients being evaluated, 34 have regularly returned for followup for a period of 12-28 weeks. Table I show the distribution as to sex, age and duration of treatment in groups A and B. The response to the therapy in each group was evaluated on the basis of a) physical work capacity ( $\mathrm{PWC}$ ), b) nitroglycerine requirement and c) electrocardiogram. PWG is considered increased if the subject could walk the treadmill longer by $50 \mathrm{M}$. or more after

Table I. Sex and Age Distribution and Duration of Treatment in Groups $\mathrm{A}$ and $\mathrm{B}$

\begin{tabular}{cc|c|c}
\hline & & A & B \\
\hline Sex & M & 11 & 12 \\
& F & 6 & 5 \\
\hline & & 17 & 17 \\
\hline & Age & $42-71$ yrs. & $40-71$ yrs. \\
& F & $40-64$ yrs. & $42-67$ yrs. \\
\hline \\
$\begin{array}{l}\text { Duration of } \\
\text { Treatment }\end{array}$
\end{tabular}


therapy as compared to the pre-treatment distance. The nitroglycerine requirement is considered decreased if the need drop down by $50 \%$. The electrocardiographic response is evaluated according to degree of change from the control ischemic ST-T depression to partial (still with junctional ST depression) or complete recovery. Table II shows that group A had more patients

Table II. Comparative Responses of Patients in Groups A and B after Treatment with Pyridinolcarbamate (or Placebo)

\begin{tabular}{l|c|c}
\hline & A & B \\
\hline $\begin{array}{c}\text { Increased physical work } \\
\text { capacity (PWC) } \\
\text { Nitroglycerine requirement } \\
\text { (less by 50\%) }\end{array}$ & 13 & 6 \\
ECG & 8 & 2 \\
Complete recovery & 6 & 1 \\
Partial Recovery & 4 & 3 \\
Length of therapy & $6-24$ weeks & $10-24$ weeks
\end{tabular}
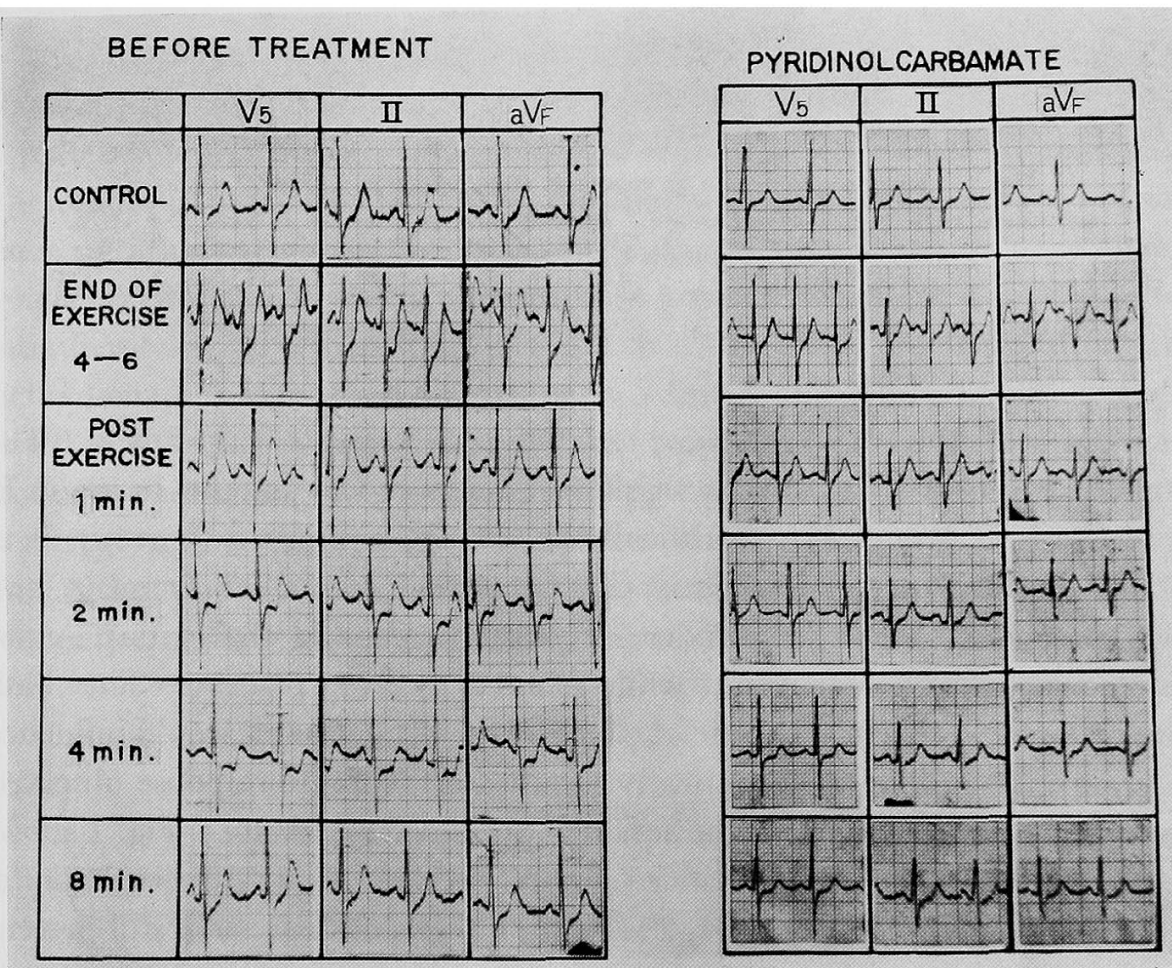

Fig. 1. Exercise ECG of a 40 years old male before and after 6 weeks of treatment with pyridinolcarbamate. Note the ischemic ST depression in $V_{5}$ and lead II during and postexercise. These changes did not appear after pyridinolcarbamate when subjected to the same degree of sub-maximal exercise. Angina of patient also disappeared after treatment. 


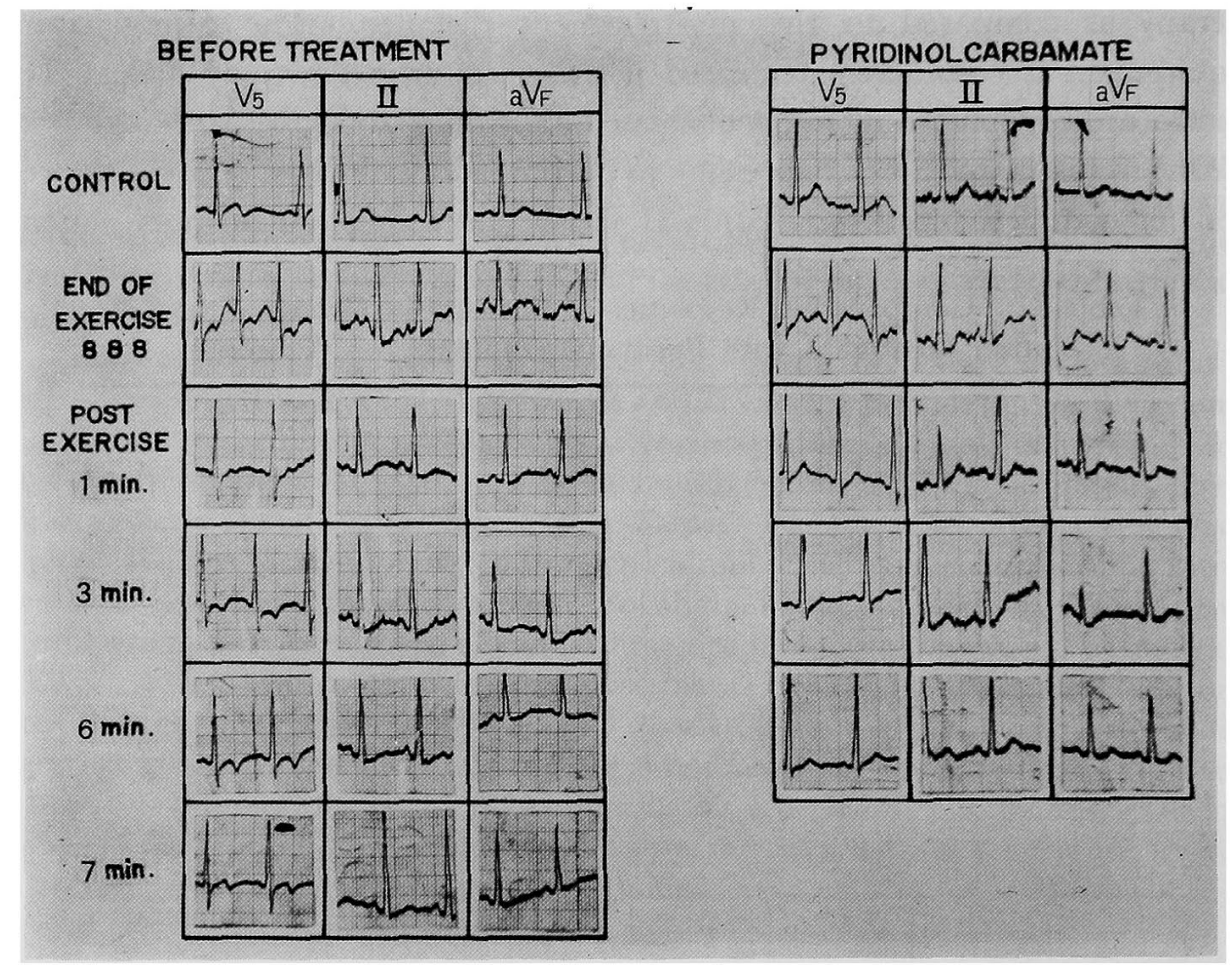

Fig. 2. Exercise EGG of a 52 years old male before and after 12 weeks of treatment with pyridinolcarbamate. After 4 min. of exercise marked " $\mathrm{J}$ " segment depression occurred in leads $\mathrm{V}_{\mathrm{j}}$, II and ${ }_{\mathrm{a}} \mathrm{V}_{\mathrm{F}}$. Ischemic ST depression followed 2-4 min. post-exercise. After treatment, the patient tolerated a longer exercise and only minimal " $\mathrm{J}$ " segment depression appeared.

responding favorably to the therapy compared to patients in group $B$. The response in group $\mathrm{A}$ is statistically significant compared to patients in group $\mathrm{B}$. The response in group $A$ is statistically significant compared to group $B$ at $\mathrm{p}<0.025$ in the 3 parameters used ( $\mathrm{PWC}$, nitroglycerine requirement, and ECG). Decoding of the drug under investigation showed that group A patients received pyridinolcarbamate while group B received placebo. Since both groups received PETN, the beneficial effects of the drug if at all would influence both groups; therefore the statistically significant favorable response observed in group A could be ascribed to the action of pyridinolcarbamate. Fig. 1 shows complete recovery in the ECG after 6 weeks therapy of pyridinolcarbamate. Fig. 2 shows partial recovery i.e. 1-2 mm. "J " segment depression still present after 12 weeks of therapy. Although our criteria for a positive exercise test is ischemic ST depression of $1 \mathrm{~mm}$. or more, conversion from an ischemic ST segment to a " $\mathrm{J}$ " segment depression is still not considered normal as this finding has been found to be an intermediate or transitional stage before a completely 
normal ECG is observed.

The clinical laboratory tests show that pyridinolcarbamate produced no serious side effects on the patients who took the drug. Gastric distress in the form of vague epigastric pains and nausea was observed in 2 patients in group A. This did not necessitate discontinuing the medication since combination with an antiacid relieved the symptoms.

\section{Comments}

The beneficial effect of pyridinolcarbamate was observed as early as 9 weeks after therapy in 3 subjects and from 12-24 weeks in the remaining 7 patients. Once electrocardiographic recovery was observed, the dose was reduced to $750 \mathrm{mg}$. in 3 divided doses and maintained for 8 weeks. We have not observed any relapse despite withdrawal of the drug after 8-16 weeks. Other investigators ${ }^{6 /, 7)}$ have reported that in many cases of angina pectoris, the relapse rate after withdrawal of pyridinolcarbamate has been definitely reduced by previous long term therapy with the compound.

In human atherosclerosis, pathologic features similar to those observed in experimentally induced atherosclerosis have been clearly recognized. ${ }^{8)}$ Even in patients with advanced atherosclerotic lesions, there are still edematous and atheromatous parts which narrow the lumen of the artery and its branches. Since pyridinolcarbamate has no vaso-dilating action, it would seem that the beneficial effects observed in patients with ischemic heart disease are due to its antiatherosclerotic action, resulting in the expansion of the arterial lumen in such edematous and atheromatous parts. Burch and De Pascuale ${ }^{\text {s }}$ have suggested that an ischemic myocardial tissue may liberate bradykinin which then produces pain of angina pectoris. This perhaps will also explain the decrease in nitroglycerine requirement in a number of patients.

Although the series is small, the statistically significant results on the beneficial effects of pyridinolcarbamate warrant its use and further investigative work.

\section{RefERENCES}

1. Shimamoto, T., Numano, F., and Fujita, T.: Am. Heart J. 71 : 216, 1966.

2. Shimamoto, T., Atsumi, T., Numano, F., and Fujita, T.: Prog. Biochem. Pharmacol. 4: 597, 1968.

3. Shimamoto, T.: Am. Heart J. 76: 106, 1968.

4. Zempleny, Z. Jojda, and Mrhova, O.: Enxymens of the vascular wall in experimental atherosclerosis in the rabbit, in Sandler, M. and Bourne, G. H., editors, Atherosclerosis and its origin, New York, London, Academic Press, Inc., p. 459, 1963.

5. Guzman, S. V.: Acta Medica Philipina 6: 63, 1969. 
6. Atsumi, T., Isokane, N., Yamashita, S., Sano, T., Odakura, T., and Kurai, A.: J. Jap. Soc. Int. Med. 56: 49, 1967.

7. Ishikawa, K.: Effect of Anginin (pyridinolcarbamate) on peripheral vascular diseases-The second symposium, Tokyo, Atherosclerosis Research Foundation, 1967.

8. Shimamoto, T.: An introduction to atherogenesis and thrombogenes is in atherogenesis, First International Symposium on atherogenesis, Tokyo, 1969.

9. Burch, G. and De Pascuale, N. P.: Am. Heart J. 65: 116, 1963. 